\title{
REVISTA
}

Revista Educación

ISSN: 0379-7082

ISSN: 2215-2644

revedu@gmail.com

Universidad de Costa Rica

Costa Rica

\section{Análisis factorial de correspondencias: Estudio en creencias y estilos de enseñanza en docentes de matemática}

Espeleta Sibaja, Annia; Rodríguez Rojas, Oldemar

Análisis factorial de correspondencias: Estudio en creencias y estilos de enseñanza en docentes de matemática

Revista Educación, vol. 42, núm. 2, 2018

Universidad de Costa Rica, Costa Rica

Disponible en: http://www.redalyc.org/articulo.oa?id=44055139036

DOI: https://doi.org/10.15517/revedu.v42i2.28911

Esta obra está bajo una Licencia Creative Commons Atribución-NoComercial-SinDerivar 3.0 Internacional. 


\section{Análisis factorial de correspondencias: Estudio en creencias y estilos de enseñanza en docentes de matemática}

\section{Correspondence Analysis: Study of Beliefs and Teaching Styles in Mathematics Teachers}

Annia Espeleta Sibaja [2]

Universidad de Costa Rica, Costa Rica

annia.espeleta@ucr.ac.cr

Oldemar Rodríguez Rojas [3]

Universidad de Costa Rica, Costa Rica

oldemar.rodriguez@ucr.ac.cr
DOI: https://doi.org/10.15517/revedu.v42i2.28911

Redalyc: http://www.redalyc.org/articulo.oa?id=44055139036

Recepción: 12 Mayo 2017

Aprobación: 16 Mayo 2018

\section{ReSUMEN:}

Este artículo presenta los resultados de un estudio sobre los estilos de enseñanza y las creencias epistemológicas del profesorado de matemática de educación media, graduado de la Universidad de Costa Rica. Asimismo, dado que la investigación siguió una metodología descriptiva y correlacional, se aplicó un cuestionario de ítems de selección única a 110 docentes de matemática formados en esta universidad, para la recolección de datos (2010-2013). Por otra parte, se analizaron las dimensiones epistemológica y pedagógica vinculadas a los estilos de enseñanza mediante el análisis factorial de correspondencias (AFC), pues este permite encontrar semejanzas en proyecciones de pocas dimensiones de acuerdo con las modalidades de respuesta obtenidas. Finalmente, dichos hallazgos ofrecen un marco de referencia de supuestos relacionados con la matemática, la naturaleza de la disciplina y su enseñanza, los cuales, a su vez, son útiles para analizar las prácticas de aula y la formación de docentes.

Palabras Clave: Creencias, análisis factorial de correspondencias, docentes de matemática, educación media, estilo de enseñanza.

\section{Abstract:}

This article presents the results of a study on the teaching styles and the epistemological beliefs of the mathematics teachers of secondary education, graduated from the University of Costa Rica. Also, given that the research followed a descriptive and correlational methodology, a questionnaire of unique selection items was applied to 110 Mathematics teachers, for data collection. On the other hand, the epistemological and pedagogical dimensions linked to the teaching styles were analyzed through the Factorial Analysis of Correspondences (AFC), since this allows to find similarities in projections of few dimensions according to the response modalities obtained. Finally, these findings offer a frame of reference for assumptions related to Mathematics, the nature of the discipline and its teaching, which are useful for analyzing classroom practices and teacher training.

KEYWORDS: beliefs, correspondence analysis, math teachers, Secondary education, teaching style.

\section{INTRODUCCIÓN}

Este artículo reporta resultados de un estudio en torno a ciertas creencias epistemológicas del profesorado de matemática de la educación media, graduado de la Universidad de Costa Rica y el estilo de enseñanza.

\section{NotAS DE AUTOR}

[2] Doctora en Educación, Máster en Planificación Curricular, Bachiller en Enseñanza de la Matemática, ambos títulos de la Universidad de Costa Rica. Diploma de Analista Científica (Diplome d'Analyste Scientifique) de la Universidad Paul Sabatier, Toulouse, Francia. Docente e investigadora. Actualmente directora del Programa de Maestría en Planificación Curricular y Coordinadora de la Carrera de Enseñanza de la Matemática

[3] Doctor del U.F.R. Matemáticas de la Decisión de la Universidad de París IX - Dauphine Francia, posterior a su doctorado en la Universidad de Stanford culmina su especialización en el campo de la Minería de Datos, es Magister en Ciencias de la Computación del Instituto Tecnológico de Costa Rica y Licenciado en Matemática Pura de la Universidad de Costa Rica. Actualmente es subdirector e investigador del Centro de Investigaciones en Matemáticas Puras y Aplicadas (CIMPA), Universidad de Costa Rica. 
Este estudio partió de la premisa de que las creencias relacionadas con la matemática caracterizan, de forma particular, el estilo de enseñanza del personal docente de matemática. En este sentido, se indagan los estilos de enseñanza para dilucidar variables que intervienen y se relacionan para una mejor descripción de la labor docente en matemática, desde los rasgos comunes de acuerdo con las creencias en relación con la actividad principal del personal docente y su papel, así como actividades en los procesos de enseñanza y aprendizaje tienen relación con la creencia del papel del estudiantado y lo que se promueve como forma de aprendizaje.

El estudio de los datos se realizó mediante un análisis factorial de correspondencias, el cual relaciona las modalidades de respuesta de los sujetos encuestados con la idea de encontrar grupos de docentes con respuestas semejantes y establecer, en este caso, estilos de enseñanza. Metodología que permite el análisis de tablas de contingencia y proyecciones en subespacios de pocas dimensiones, las distancias de las respuestas en las modalidades de variables cualitativas distan del centro de la inercia, por lo que se encuentran patrones o relaciones, resultados que contribuyen con el análisis y reflexión de variables que intervienen en los estilos de enseñanza de docentes.

En matemática, son conocidas las dificultades que enfrentan estudiantes para el logro de aprendizajes, entre ellas las asociadas con factores relacionados con docentes (Chronaki , 2000; Contreras, 1994). La profesión docente es compleja, quien educa enfrenta situaciones inesperadas, pues trabaja con estudiantes en contextos diversos y dinámicos. En este campo de estudio, Bonilla (1986), refiriéndose a la docencia, afirma "es un delicado entretejido de hilos que confluyen no solo los profesores sino los alumnos y el medio educativo en una complicada estructura de relaciones. Son por lo tanto muchas variables involucradas en tan importante acto humano" (p. 100).

De acuerdo con Vázquez y Angulo (2010), la docencia obedece a una manera de entender no solo la enseñanza, sino también la acción humana. Asimismo, pensar en la enseñanza ha supuesto la búsqueda de patrones de actuación y aceptar las opciones metodológicas supone siempre una toma de decisión con respecto a la propia práctica. Las características que determinan estilos de enseñanza de docentes tienen relación con innumerables variables, en particular las que intervienen con el actuar docente y sus creencias acerca de la matemática, su enseñanza y su aprendizaje.

Entre los intentos clasificatorios de estilos de enseñanza, están los citados por Oser y Baeriswyl (2001), quienes utilizan la expresión coreografía de la enseñanza para referirse a los aspectos metodológicos de esta. Estos autores señalan dos niveles, uno explícito, que comprende las acciones de docentes, sus improvisaciones y adaptaciones a las demandas del aula; y el denominado modelo básico, relacionado con las operaciones empleadas en el proceso psicológico individual.

Se distinguen, principalmente, dos tendencias en estilos de enseñanza, una de tradición psicológica, centrada principalmente en la correspondencia entre estilos cognitivos y de aprendizaje de estudiantes y la otra de tradición pedagógica, que los define a partir de la cualificación docente, y que identifica concepciones y creencias frente a la labor educativa (Camargo y Hederich, 2007, citados en Abello y Hernández, 2010).

\section{REFERENTE TEÓRICO}

La revisión bibliográfica acerca de estilos de enseñanza genera variedad de términos, entre ellos, se emplea el estilo de docencia, para referirse al modo de enseñar y de trabajar de docentes (Gargallo, 2008). De León (2006), al referirse a "Modelos de enseñanza" y "Estilos de enseñanza", menciona que en muchas investigaciones, entre ellas la de Díaz Barriga y Hernández, ambos términos son sinónimos.

De León (2006) menciona que muchos estudios se abordan desde las características que deberían estar presente en la praxis de cada docente, tales como el "deber ser" (Clark y Peterson, 1990; Díaz Barriga, 1999; Gimeno Sacristán, 1993).

Algunas investigaciones se centran en determinar categorías e indicadores de los estilos de enseñanza y su relación con el aprendizaje (Vaugh y Baker, 2008; Martínez, 2009); otras, la eficacia o las respuestas a 
determinados modelos, como los centrados en el estudiantado (Gargallo, 2008). Esta tendencia apunta a evaluar el logro académico, así como la importancia de una instrucción de calidad. Lo anterior genera una línea de investigación donde interesa reflexionar y evaluar los modelos o estilos de enseñanza que el personal docente adopte, su relación con las exigencias del medio, la pertinencia e idoneidad de quien esnseña y las nuevas dinámicas de aula.

Evans (2006, p. 12) menciona que los estilos describen qué es lo que la gente hace y cita a Schmeck (1888) quien define estilos como: “... any pattern we see in a person's way of accomplishing a particular type of task [ cualquier patrón que vemos en las personas es una forma particular de cumplir un tipo de tarea]"

En este estudio se determina una clasificación de estilos de enseñanza que contempla aspectos de dos dimensiones, la pedagógica y la afectiva referida a las creencias epistemológicas.

La dimensión pedagógica significa agrupar lo relacionado con la práctica docente o el hecho educativo, las decisiones del profesorado en cuanto a las metodologías de enseñanza y aprendizaje, los métodos de evaluación, el ambiente y formas de trabajo que propicia.

Francis (2012) complementa la idea anterior al plantear que "la dimensión pedagógica constituye aquellas visiones y acciones que tiene el docente acerca de cómo debe ser el proceso educativo y, en el caso particular, el proceso formativo" (p. 28).

Blouin (1987) y Burton (1986), citados en Lafortune (1992. p. 8), señalan cada uno a su manera que "soulignent, chacun à leur façon, que les attitudes du personnel enseignant jouent aussi un rôle important dans l'apprentissage de cette discipline [las actitudes del personal docente juegan un rol importante en el aprendizaje de esta disciplina]".

Por su parte, Caballero (2008), refiriéndose a la dimensión afectiva, señala que "en Educación Matemática esta línea está orientada hacia la educación de los afectos, creencias, actitudes y emociones como determinantes de la calidad de los aprendizajes (McLeod, 1989, 1992, Gómez-Chacón, 1997, 1998, Goldin, 1988)" (p. 28).

Las creencias y concepciones son difíciles de definir, pues se usan con distintos significados, como los constructos con intenciones similares: filosofías personales y cosmovisiones (Ponte, 1999). Algunos estudios como los de Thompson (1992), citados en Ponte (1999), caracterizan concepciones como "una estructura mental general, abarcando creencias, los significados, conceptos, las proposiciones, reglas, las imágenes mentales, preferencias y gustos".

Otras investigaciones de corte psicológico orientan las creencias en la psicología cognitiva de los años setenta, donde se reportan numerosos estudios. En esta línea, Contreras y Blanco (2002) estudian las concepciones y creencias del profesorado que condicionan el desarrollo y la actuación profesional. En otros resultados, Heimlich y Norland (2002) afirman que las estrategias de enseñanza se implementan en función de las propias creencias.

Nespor (1987), citado por Ponte (1999), trabajó la naturaleza de las matemáticas, su enseñanza y aprendizaje, desde la premisa de que para entender la enseñanza de la matemática desde las perspectivas de los maestros y maestras, se debe entender las creencias con las cuales definen y practican su trabajo.

Aunado a resultados de creencias, Caballero (2008) establece categorías $o$ tipología de creencias, que se han considerado en este estudio: creencias acerca de la naturaleza de las matemáticas, de la enseñanza y su aprendizaje. Estas creencias epistemológicas involucran poco componente afectivo, pero constituyen una parte importante del contexto en el cual se desarrolla el afecto, determinando manifestaciones y comportamientos en docentes y estudiantes.

En resultados de un estudio acerca de las creencias en estudiantes en formación para ser maestros y maestras, se encuentra que estas mismas van a determinar su propio aprendizaje y en el futuro su enseñanza (Blanco y Guerrero, 2002). Por lo que las creencias podrían condicionar, de alguna manera, aptitudes, motivación, logro o expectativas de estudiantes ante el aprendizaje y su enseñanza. 
Otro tipo de creencias, las que tienen que ver con uno mismo o una misma como aprendiz de matemáticas, tienen una fuerte carga afectiva e incluyen la confianza, al autoconcepto, la atribución causal del éxito y fracaso escolar (Gómez-Chacón, 1997, citado en Caballero, 2008). Asimismo, la confianza de cada persona en sí misma juega un papel importante en los logros matemáticos del estudiantado, como lo muestran resultados en los estudios sobre actitudes (Aiken, 1979; Hart y Walter, 1993).

Las creencias en relación con el autoconcepto del estudianado como aprendiz de matemáticas es una de las variables más influyentes en la enseñanza-aprendizaje de dicha materia, estas forman conocimientos subjetivos (creencias, cogniciones), las emociones y las intenciones de acción acerca de la pesona misma respecto a la materia. De igual manera, entre los elementos que gozan de mayor importancia están el interés, la eficiencia en matemáticas, la motivación y el placer con la materia, la atribución de éxito o fracaso escolar y el autoconcepto como miembro de un grupo social (Gómez-Chacón, 2000, citado en Caballero, 2008).

El estilo atribucional del sujeto, junto al autoconcepto, son algunos de los principales factores que determinan la dimensión afectiva y emocional del aprendizaje. El patrón más favorable es aquel en el cual el estudiantado atribuye sus éxitos o fracasos a causas internas y variables controlables, como pueden ser el esfuerzo personal, la planificación y organización del trabajo (Miras, 2001, citado en Caballero, 2008).

Sobre las creencias acerca del papel del profesorado de matemáticas, hay un tipo de creencias que considera tanto el papel docente como el estudiantil, condicionado por las experiencias vividas en la formación universitaria, el conocimiento de las teorías de la educación y otros aspectos que podrían influir en los estilos de enseñanza.

Blanco y Guerrero (2002) mencionan que el papel del profesorado de matemática relaciona conocimientos con las expectativas, motivación y autoconfianza que se genere en el estudiantado, con lo que le posibilita un mayor rendimiento y el desarrollo armónico de su personalidad.

Con respecto a las creencias sobre el contexto social, estas tienen que ver con la utilidad o el valor asignado al aprendizaje de la matemática en la vida cotidiana y cómo podrían afectar en la situación de enseñanza y aprendizaje. Asimismo, la decisión de estudiar o trabajar como docente de matemática podría influir en las actitudes y emociones ante esta disciplina, su enseñanza y aprendizaje.

Ponte (1999) señala la existencia de una relación entre actitudes y creencias cuando estas últimas se consideran como disposiciones hacia la acción. Además, menciona que la mayoría de estudios les atribuyen una carga afectiva importante, pues están relacionadas con preferencias, inclinaciones y líneas de acción, por lo que pueden mostrar aspectos afectivos de la personalidad del profesorado.

En este estudio, mediante el análisis factorial de correspondencias, las variables de las dimensiones pedagógica y epistemológica se agrupan según las modalidades de respuestas y determinan clasificaciones que caracterizan los estilos de enseñanza de docentes.

\section{Metodología}

La investigación se define descriptiva y transversal, la recopilación de información se da en un momento específico del 2010 al 2013. Asimismo, es de carácter correlacional, se buscan las relaciones entre las modalidades de respuestas y las características de docentes participantes en el estudio.

Se selecciona intencionalmente una muestra aleatoria de docentes que se han graduado de la carrera de Enseñanza de la Matemática de la UCR, se consideran las bases de datos del Ministerio de Educación Pública (MEP). El tipo de muestreo seleccionado es por conglomerados en dos etapas, emplea en la primera etapa la distribución y selección de colegios, de forma proporcional entre públicos y privados; en la segunda etapa, se toma en cuenta la totalidad de docentes de los colegios seleccionados en la primera etapa. Este diseño de conglomerados completos permitió reducir costos y mejorar la precisión de las estimaciones. Se obtienen 110 cuestionarios completos de docentes de matemática que laboran en la secundaria, el estudio no tiene fines inferenciales. 
El diseño del cuestionario denominado Cuestionario de estilos de enseñanza de docentes de matemática (EEDM) tomó en cuenta los resultados de la revisión bibliográfica, así como la validación de personal experto en la construcción de ítems de las dimensiones pedagógica y epistemológica. Este instrumento se sometió a pruebas estadísticas que aportan los criterios técnicos para su depuración a partir de los resultados de la prueba piloto. El instrumento seleccionado fue el modelo más simple (reducido en ítems) y el de mejor ajuste. En anexo se presentan los ítems analizados y su codificación.

Para el análisis de la información se utiliza el análisis factorial de correspondencias, mediante el programa PIMAD y el paquete RSDA desarrollados por el Dr. Oldemar Rodríguez Rojas, que incluyen una gran cantidad de métodos de análisis de datos clásicos y simbólico, entre ellos el análisis factorial de correspondencias para datos multievaluados. También se utilizó el paquete 'FactoMineR', versión 1.14, Multivariate Exploratory Data Analysis and Data Mining with R, de Francois Husson, Julie Josse, Sebastien Le, Jeremy Mazet y Maintainer Francois Husson.

La aplicación del análisis factorial de correspondencias (en adelante AFC), ha permitido elaborar nuevos métodos de tratamiento de datos, para visualizar, estructurar, modelizar y explicar fenómenos. Un caso particular de estos análisis se pone en evidencia en la didáctica de la matemática, las tareas en la resolución de ejercicios o la contribución de ciertas categorías de estudiantes para obtener resultados (Gras, 1992).

El AFC tiene por objetivo encontrar relaciones o patrones en las modalidades de respuestas que se han organizado en una tabla de contingencia asociada y provenientes de variables cualitativas (Rodríguez, 2007).

Se pretende resumir la información y proyectarla en un subespacio de pocas dimensiones, factores o ejes en un mapa bidimensional en donde se pueden observar con mayor facilidad las asociaciones entre las modalidades de respuesta, cercanía u oposición. Estos ejes sintéticos pueden ser el resultado de la influencia de una o muchas modalidades de dos variables.

Para iniciar el análisis es necesario convertir la información de una matriz con las respuestas de las variables cualitativas a una matriz binaria. Sea s el número de variables y n el número de individuos. En la entrada (i,j) de la matriz K aparece la cantidad de individuos que presentan simultáneamente la modalidad i de la variable $\mathrm{X}$ y la modalidad $\mathrm{j}$ de la variable $\mathrm{Y}$.

En el siguiente ejemplo se ilustra esta transformación:

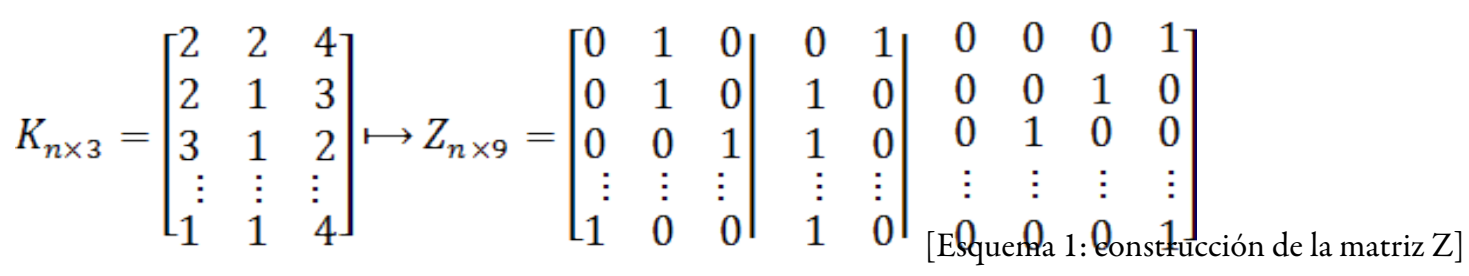

Con la metodología utilizada para construir la matriz binaria $\mathrm{Z}$, a partir de esta matriz $\mathrm{K}$, con $\mathrm{n}$ filas y $\mathrm{p}$ columnas que describen las respuestas de los $\mathrm{n}$ individuos por el código binario de 0 y 1 . Esta matriz $\mathrm{Z}$ es llamada tabla disjuntiva completa, donde en términos generales se escribe: $=1 \mathrm{o}=0$, (Lebart, Morineau y Piron (2000), según el sujeto i selecciona o no la modalidad j de la pregunta.

La matriz $Z$, tiene $n$ filas y pq columnas, es tal que $Z$ describe la partición de los $n$ individuos y las respuestas de la pregunta q. Los datos de las preguntas tienen la forma disjuntiva.

El conjunto de pq modalidades de respuesta se puede particionar en pq clases. Los datos de dos preguntas llevadas bajo la forma disjuntiva completa, permiten realizar dos particiones del conjunto de individuos encuestados y se obtiene una matriz de contingencia.

Sea $B=$, llamada tabla de contingencia de Burt, asociada a la matriz disjuntiva Z. Se denomina D la matriz diagonal de orden ( $\mathrm{p}, \mathrm{p})$ que tiene los mismos elementos diagonales que B son las frecuencias correspondientes 
a cada modalidad de respuesta, mediante esta se inician los análisis de correspondencias y se proyectan en planos que valoran la inercia y la representatividad.

El AFC se utilizará para cruzar variables cualitativas de dos en dos y ver cómo se interrelacionan sus modalidades de respuesta. La asociación de modalidades entre variables distintas permite visualizar la proximidad entre individuos en términos de sus respuestas parecidas; resultados que se podrían analizar desde las características de los grupos que se conforman en las proyecciones de las variables. Es decir, por ejemplo, la respuesta $\mathrm{A}$ de la variable $\mathrm{X}$ queda cerca de la respuesta $\mathrm{B}$ de la variable $\mathrm{Y}$ significa que quienes seleccionaron la modalidad de respuesta $\mathrm{A}$ de la variable $\mathrm{X}$ también seleccionaron la modalidad $\mathrm{B}$ de la variable $\mathrm{Y}$.

A continuación se presentan resultados de los análisis de pares de ítems que relacionan las creencias y la dimensión pedagógica para caracterizar estilos de enseñanza.

\section{ANÁLISIS DE RESULTADOS}

El análisis de resultados se realiza mediante las salidas que relacionan variables de dos en dos y que agrupa respuestas de docentes según tipo de creencia.

\section{En relación con las creencias de la naturaleza de la Matemática}

En la Tabla 1, se describen las modalidades de respuesta de los ítems p.1.2 Naturaleza de la matemática y la p.1.3 (Figura 1) Actividad principal del personal docente, representadas mediante el AFC de la Tabla 1, relación que reporta una inercia de $75,5 \%$ y se conforman tres agrupaciones. 
TABLA 1

Creencia de la naturaleza de la matemática y su relación con la actividad principal del personal docente

\begin{tabular}{|c|c|c|c|c|}
\hline Variables & $\begin{array}{c}1.2 \mathrm{Es} \mathrm{la} \\
\text { matemática } \\
\text { principalmente: }\end{array}$ & $\begin{array}{r}1.3 \text { La activ } \\
\text { principal } \\
\text { personal do } \\
\text { es: }\end{array}$ & $\begin{array}{l}\text { dad } \\
\text { el } \\
\text { ente }\end{array}$ & $\begin{array}{c}\text { Análisis de un estilo de } \\
\text { enseñanza }\end{array}$ \\
\hline \multirow[t]{3}{*}{$\begin{array}{l}\text { Modalidades } \\
\text { de respuesta } \\
\text { por } \\
\text { agrupación }\end{array}$} & $\begin{array}{l}\text { Una ciencia en sí } \\
\text { misma } \\
\text { Un lenguaje }\end{array}$ & $\begin{array}{l}\text { Lograr que } \\
\text { estudiantes } \\
\text { aprendan. } \\
\text { Motivar a } \\
\text { estudiantes } \\
\text { aprender }\end{array}$ & sus & $\begin{array}{l}\text { La rigurosidad de la } \\
\text { disciplina y el conocimiento } \\
\text { sigue siendo el foco de la } \\
\text { actividad docente, logros de } \\
\text { aprendizajes y motivación. } \\
\text { Una educación academicista } \\
\text { con énfasis en la ciencia y el } \\
\text { aprendizaje. Una enseñanza } \\
\text { centrada en la disciplina y } \\
\text { en el aprendizaje }\end{array}$ \\
\hline & 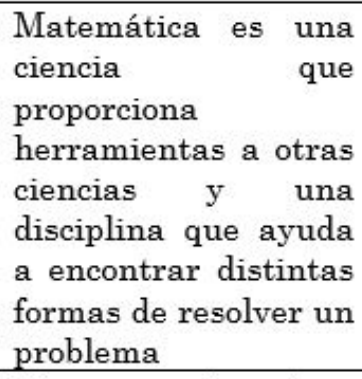 & \multicolumn{2}{|c|}{ Impartir contenidos } & $\begin{array}{l}\text { La creencia de que la } \\
\text { matemática apoya otras } \\
\text { ciencias y ayuda a resolver } \\
\text { problemas, relaciona la } \\
\text { actividad docente de } \\
\text { transmisión y permite } \\
\text { interrelacionar } \\
\text { disciplinas. } \\
\text { práctica y útil. }\end{array}$ \\
\hline & $\begin{array}{l}\text { Una disciplina } \\
\text { formativa que ayuda } \\
\text { a desarrollar el } \\
\text { pensamiento y la } \\
\text { lógica }\end{array}$ & \multicolumn{2}{|c|}{$\begin{array}{l}\text { Utilizar } \\
\text { metodologías de } \\
\text { enseñanza } \\
\text { atractivas. } \\
\text { Organizar } \\
\text { presentar y } \\
\text { conocimiento de } \\
\text { forma comprensible. } \\
\text { Formar ciudadanía } \\
\text { crítica. }\end{array}$} & $\begin{array}{l}\text { Estas creencias relacionan } \\
\text { una enseñanza centrada en } \\
\text { el estudiantado, se utilizan } \\
\text { metodologías atractivas y se } \\
\text { interesa en la transposición } \\
\text { didáctica y en formar } \\
\text { estudiantado crítico. }\end{array}$ \\
\hline
\end{tabular}




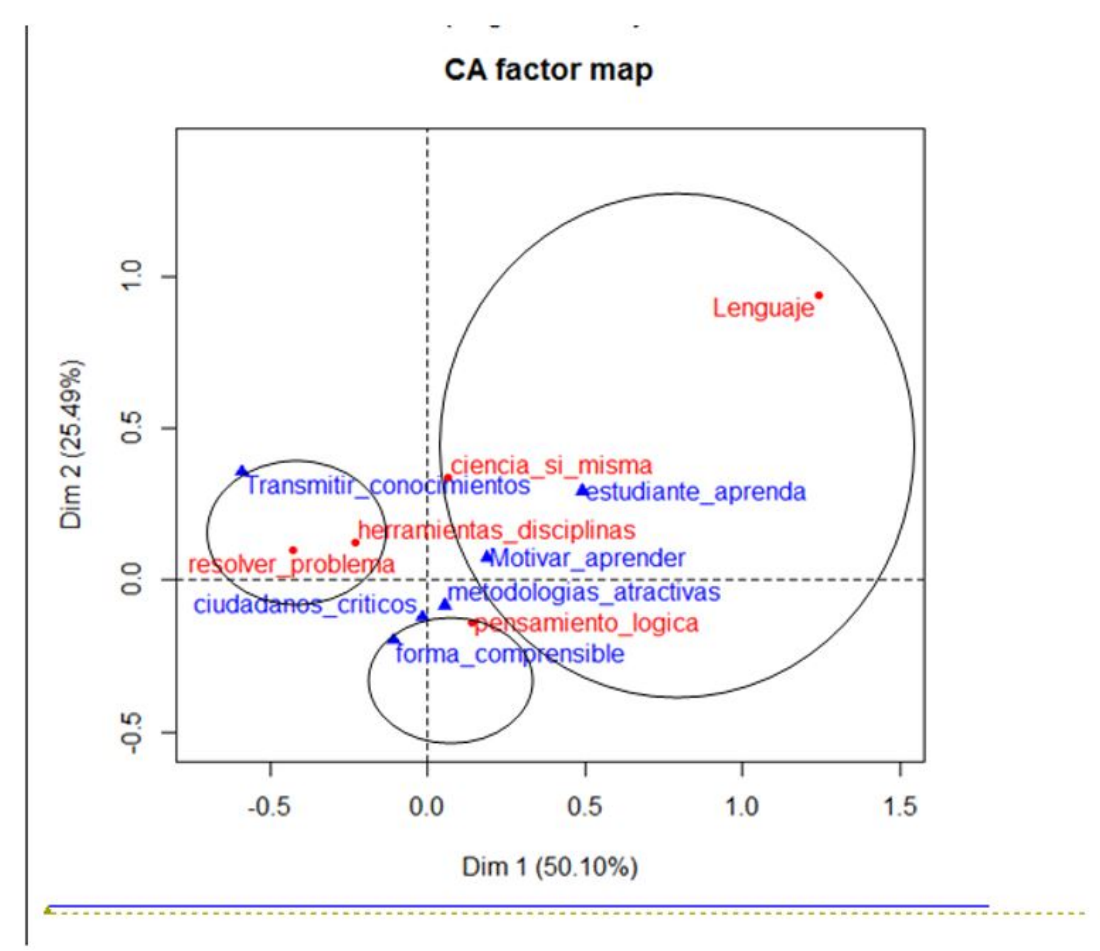

FIGURA 1

Relación de las modalidades de respuesta de las preguntas 1.2 y 1.3 .

La Tabla 2 describe el AFC de las respuestas a los ítems 1.2 Naturaleza de la matemática y 1.4 (Figura 2) El papel estudiantil. El análisis arroja tres agrupaciones con una inercia de 92,06\%. 
TABLA 2

Creencia de la naturaleza de la matemática y su relación con el papel del estudiantado

\begin{tabular}{|c|c|c|c|}
\hline Variables & $\begin{array}{c}1.2 \mathrm{Es} \mathrm{la} \\
\text { matemática } \\
\text { principalmente: }\end{array}$ & $\begin{array}{l}1.4 \mathrm{El} \text { papel de } \\
\text { estudiantes es }\end{array}$ & $\begin{array}{c}\text { Análisis de un estilo de } \\
\text { enseñanza }\end{array}$ \\
\hline $\begin{array}{l}\text { Modalidades } \\
\text { de respuesta } \\
\text { por } \\
\text { agrupación }\end{array}$ & $\begin{array}{l}\text { Una disciplina } \\
\text { formativa que } \\
\text { ayuda a desarrollar } \\
\text { el pensamiento y la } \\
\text { lógica. } \\
\text { Una disciplina que } \\
\text { ayuda a encontrar } \\
\text { distintas formas de } \\
\text { resolver un } \\
\text { problema }\end{array}$ & $\begin{array}{l}\text { Prestar atención y } \\
\text { tomar bien los } \\
\text { apuntes. } \\
\\
\text { Participar } \\
\text { activamente en } \\
\text { situaciones de } \\
\text { aprendizaje }\end{array}$ & $\begin{array}{l}\text { Se relaciona el papel del } \\
\text { estudiantado con alguien } \\
\text { que presta atención y que } \\
\text { participa activamente en } \\
\text { las situaciones de } \\
\text { aprendizaje. Se le atribuye } \\
\text { responsabilidad. } \\
\text { Enseñanza activa y } \\
\text { formativa, en el } \\
\text { responsabilidades en estudiantado. }\end{array}$ \\
\hline & $\begin{array}{l}\text { Un lenguaje } \\
\text { Una ciencia en sí } \\
\text { misma }\end{array}$ & $\begin{array}{l}\text { Reflexionar y } \\
\text { mostrar criticidad } \\
\text { de los conocimientos } \\
\text { estudiados }\end{array}$ & $\begin{array}{l}\text { Se da énfasis a la } \\
\text { estructura, lenguaje, } \\
\text { propiedades y rigurosidad } \\
\text { de la matemática como } \\
\text { ciencia, por lo que se } \\
\text { promueve la reflexión de lo } \\
\text { estudiado. Enseñanza } \\
\text { centrada en el estudiantado } \\
\text { y en los contenidos }\end{array}$ \\
\hline & $\begin{array}{l}\text { Una ciencia que } \\
\text { proporciona } \\
\text { herramientas a } \\
\text { otras disciplinas }\end{array}$ & $\begin{array}{l}\text { Responder lo } \\
\text { solicitado por el } \\
\text { personal docente }\end{array}$ & $\begin{array}{l}\text { Se observa que, en el papel } \\
\text { estudiantil, el responder lo } \\
\text { solicitado por su docente es } \\
\text { afin con cumplir las } \\
\text { responsabilidades } \\
\text { asignadas por su docente. } \\
\text { Estudiante que cumple } \\
\text { responsabilidades y una } \\
\text { matemática útil, práctica, } \\
\text { que proporciona } \\
\text { herramientas a otras } \\
\text { disciplinas, pero se asigna } \\
\text { la responsabilidad al } \\
\text { personal docente. }\end{array}$ \\
\hline
\end{tabular}




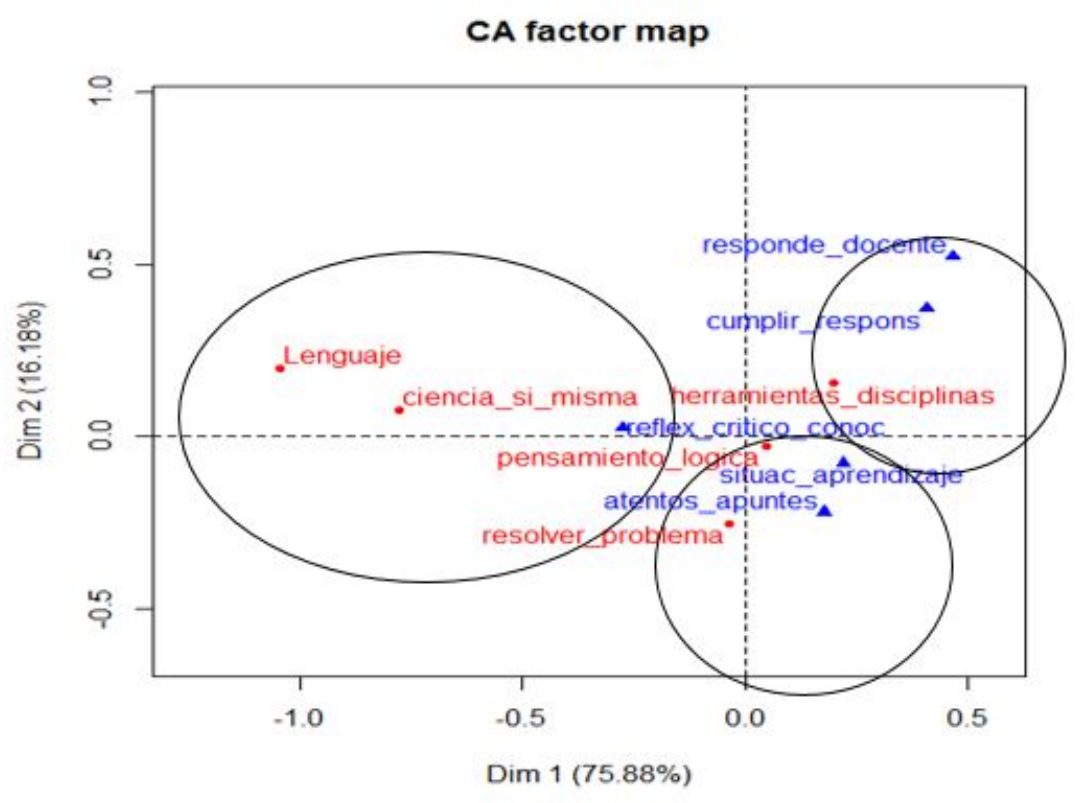

FIGURA 2

Relación de las modalidades de respuesta de las preguntas 1.2 y 1.4

\section{En relación con el aprendizaje}

En cuanto al AFC de las creencias epistemológicas relacionadas con el aprendizaje, se han considerado las relacionadas con el papel del estudiantado, la actividad principal del personal docente y lo que se promueve como forma de aprendizaje. En la Tabla 3 y la Figura 3, se muestra la agrupación según las modalidades de respuesta de las variables: p.1.4 el papel del estudiantado y p.1.9 lo que promueve el personal docente como forma de aprendizaje, la cual presenta una inercia de $83,61 \%$ en una conformación de tres grupos. 
TABLA 3

El papel del estudiantado y su relación con lo que

promueve el personal docente como forma de aprendizaje

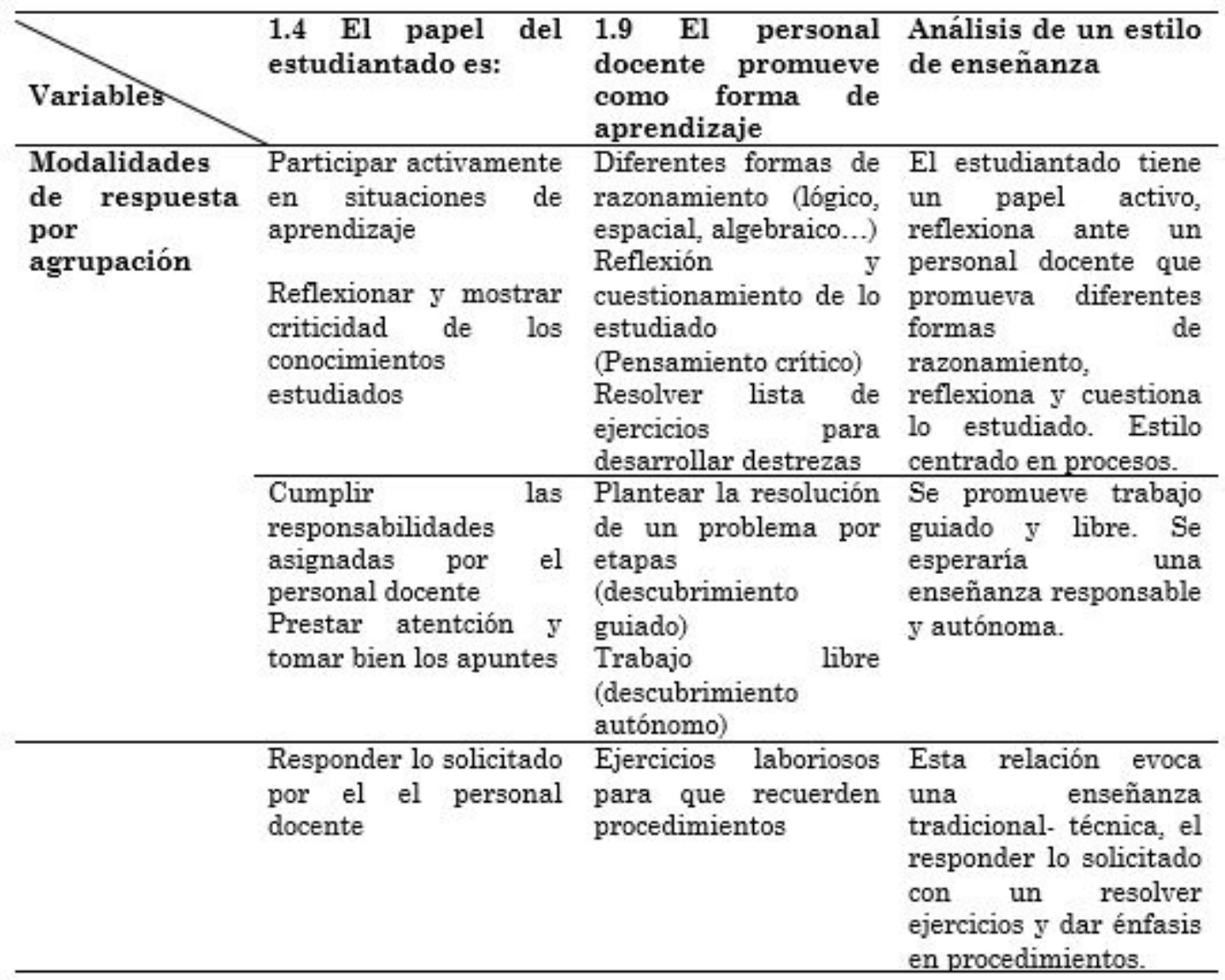




\section{CA factor map}

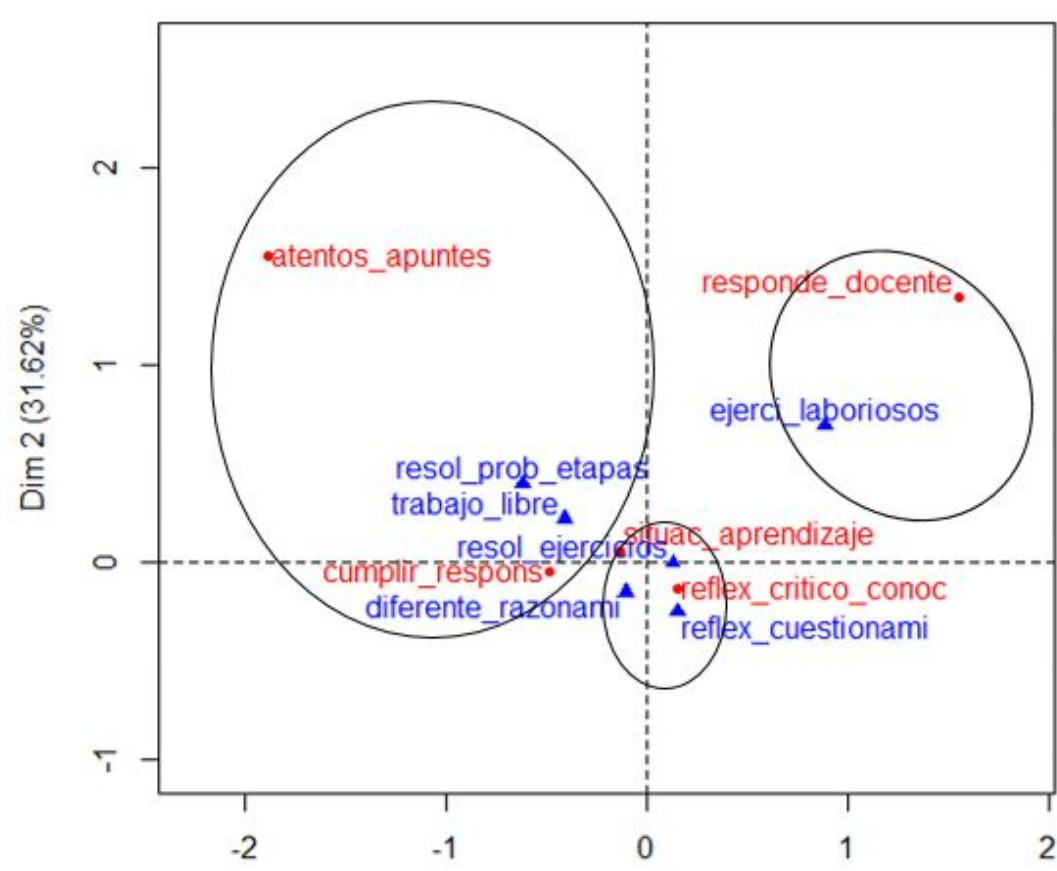

$\operatorname{Dim} 1(51.99 \%)$

FIGURA 3

Relación de las modalidades de respuesta de las preguntas 1.4 y 1.9.

Estos resultados evidencian respuestas afines de la creencia de docentes en cuanto al papel del estudiantado y lo que promueven como forma de aprendizaje. Relaciones que describen: personal docente innovador y estudiantado activo; personal docente que guía y da libertad con estudiantado autónomo y, por último, personal docente técnico y estudiantado que responde lo solicitado.

Por otro lado, en el análisis de correspondencias de las preguntas de la Tabla 4: p.1.3 la actividad principal del personal docente y p.3.2 la influencia del personal docente por el aprendizaje de estudiantado, se obtienen dos grupos: uno que le da mucha importancia a motivar al estudiantado por el aprendizaje y otro por el trabajo del personal docente en su organización y el rendimiento. Resultados proyectados en la Figura 4 con una inercia de $80,29 \%$. 
TABLA 4

Actividad principal del personal docente y su influencia

\begin{tabular}{|c|c|c|c|}
\hline Variables & $\begin{array}{l}\text { p.1.3 La actividad } \\
\text { principal del } \\
\text { personal docente es: }\end{array}$ & $\begin{array}{l}\text { p.3.2 El personal } \\
\text { docente influye } \\
\text { principalmente }\end{array}$ & $\begin{array}{l}\text { Análisis de un estilo } \\
\text { de enseñanza }\end{array}$ \\
\hline $\begin{array}{l}\text { Modalidades } \\
\text { de respuesta } \\
\text { por } \\
\text { agrupación }\end{array}$ & $\begin{array}{l}\text { Formar ciudadanía } \\
\text { crítica } \\
\text { Impartir contenidos } \\
\text { Motivar al } \\
\text { estudiantado por } \\
\text { aprender } \\
\text { Lograr que el } \\
\text { estudiantado aprenda } \\
\text { Utilizar metodologías } \\
\text { de enseñanza } \\
\text { atractivas }\end{array}$ & 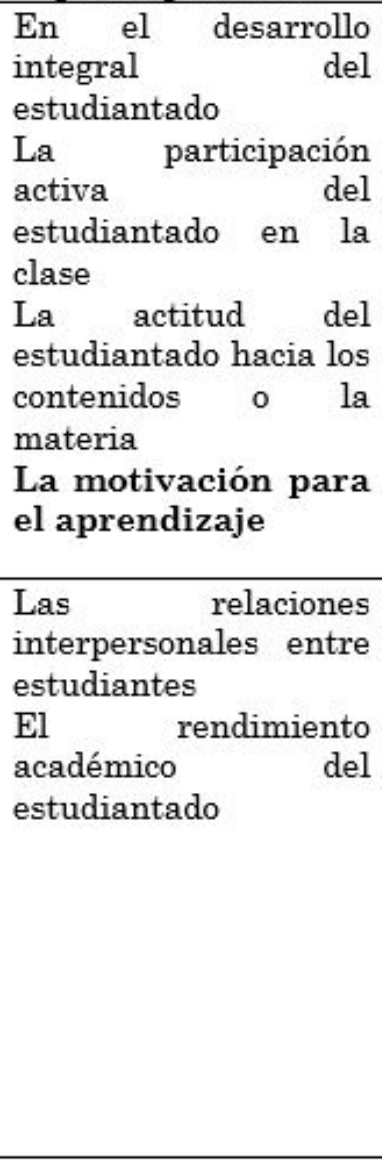 & 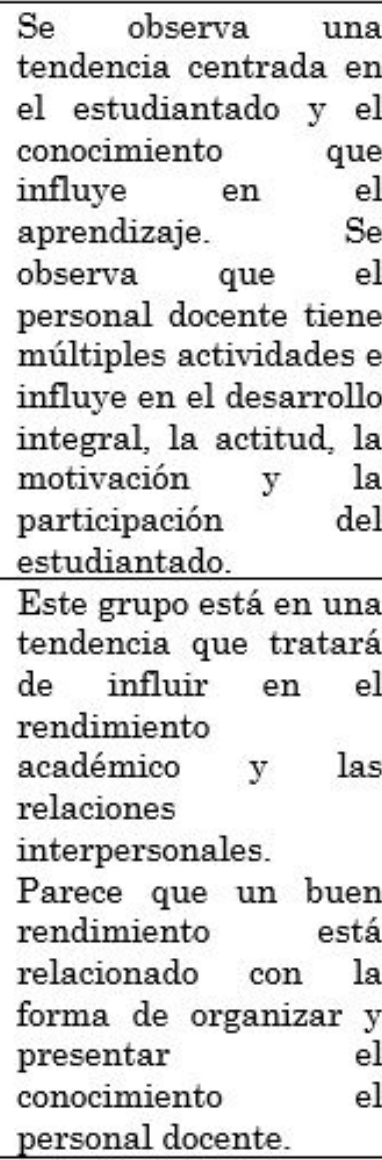 \\
\hline
\end{tabular}




\section{CA factor map}

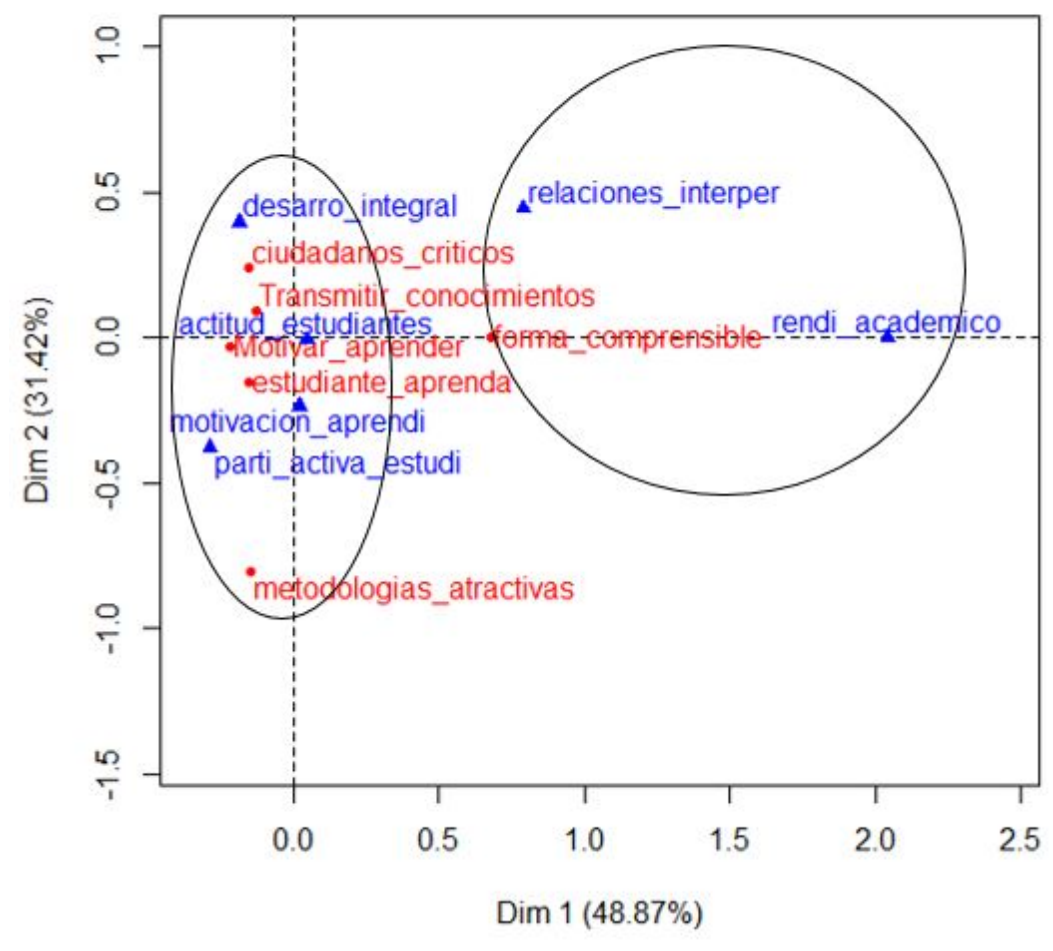

FIGURA 4

Relación de las modalidades de respuesta de las preguntas 1.3 y 3.2 .

\section{En relación con la enseñanza}

El AFC que relaciona creencias acerca de la enseñanza considera preguntas del papel del estudiantado (p.1.4), las actividades que predominan en la clase (p.1.7) y las actividades principales del personal docente (p.1.3).

En las respuestas a las preguntas 1.3 y 1.4 se obtienen tres grupos representados en la Figura 5, que se analizan en la Tabla 5, presentan una inercia de $87,6 \%$. 


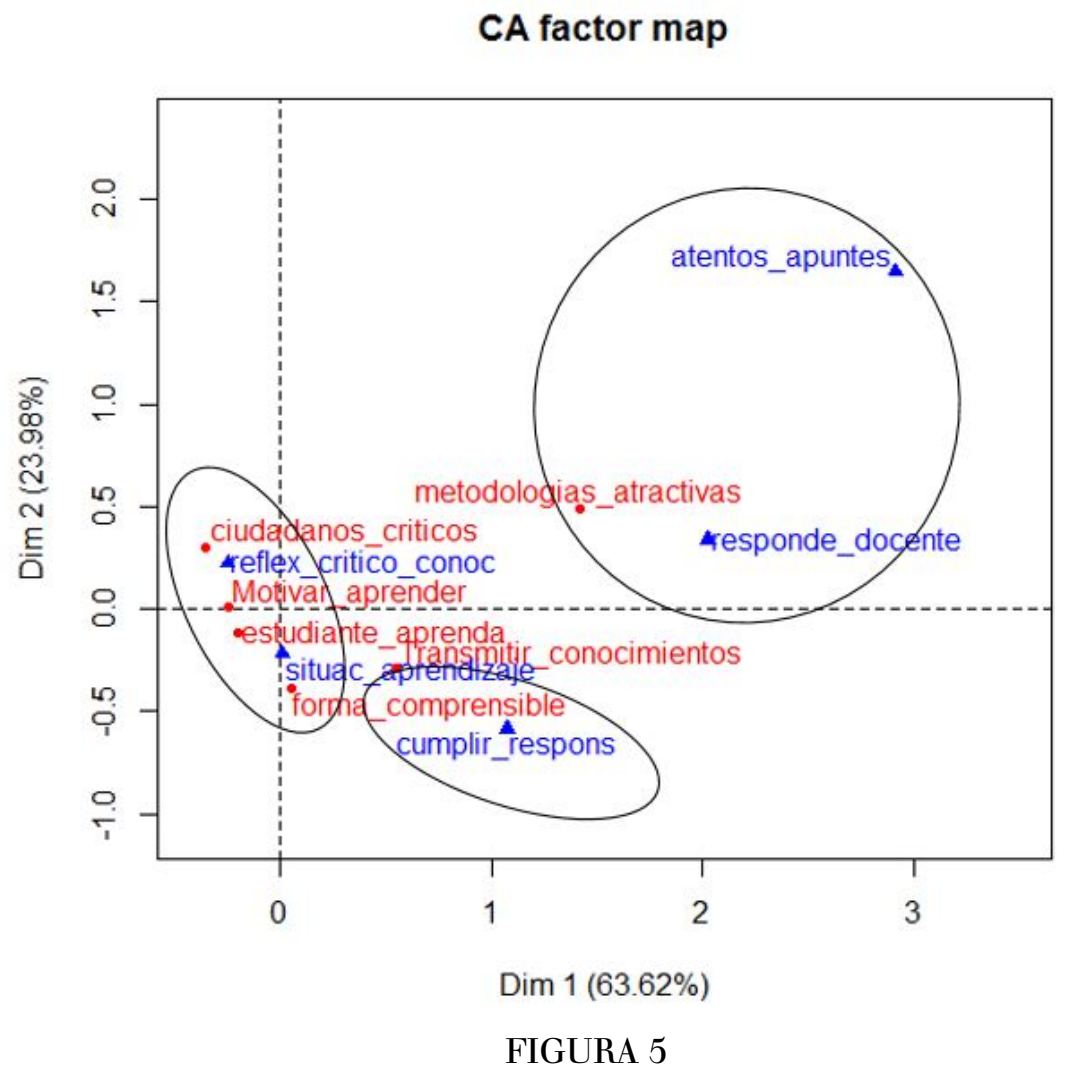

Relación de las modalidades de respuesta de las preguntas 1.3 y 1.4. 
TABLA 5

Relación entre la actividad principal del personal docente y el papel del estudiantado

\begin{tabular}{|c|c|c|c|}
\hline 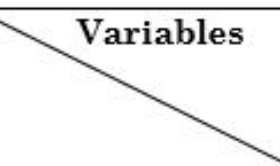 & $\begin{array}{c}1.3 \mathrm{La} \text { actividad } \\
\text { principal del } \\
\text { personal docente es: }\end{array}$ & $\begin{array}{l}1.4 \mathrm{El} \text { papel del } \\
\text { estudiantado es }\end{array}$ & $\begin{array}{c}\text { Análisis de un estilo } \\
\text { de enseñanza }\end{array}$ \\
\hline \multirow[t]{5}{*}{$\begin{array}{l}\text { Modalidades } \\
\text { de respuesta } \\
\text { por } \\
\text { agrupación }\end{array}$} & $\begin{array}{lr}\text { Utilizar metodologías } \\
\text { de } & \text { enseñanza } \\
\text { atractivas } & \end{array}$ & $\begin{array}{lll}\text { Responder } & \text { lo } \\
\text { solicitado por el } \\
\text { personal docente }\end{array}$ & $\begin{array}{l}\text { Utilizar metodologías } \\
\text { de enseñanza } \\
\text { atractivas, con un rol } \\
\text { activo del estudiantado }\end{array}$ \\
\hline & & $\begin{array}{l}\text { Prestar atención y } \\
\text { tomar bien los apuntes }\end{array}$ & $\begin{array}{l}\text { en cuanto a resultados } \\
\text { de sus trabajos. }\end{array}$ \\
\hline & Impartir contenidos & $\begin{array}{ll}\text { Cumplir } & \text { las } \\
\text { responsabilidades } & \\
\text { asignadas por } & \text { el } \\
\text { personal docente } & \end{array}$ & $\begin{array}{l}\text { Impartir contenidos y } \\
\text { cumplir } \\
\text { responsabilidades } \\
\text { asignadas por el } \\
\text { personal docente, es la } \\
\text { relación de un estilo de } \\
\text { enseñanza tradicional }\end{array}$ \\
\hline & $\begin{array}{lr}\text { Lograr } & \text { que } \\
\text { elestudiantado } & \\
\text { aprenda } & \\
\text { Motivar } & \text { al } \\
\text { estudiantado } & \text { por } \\
\text { aprender } & \end{array}$ & $\begin{array}{l}\text { Participar } \\
\text { activamente en } \\
\text { situaciones } \\
\text { aprendizaje } \\
\text { Reflexionar y mostrar }\end{array}$ & $\begin{array}{ll}\text { Este grupo representa } \\
\text { una } & \text { enseñanza } \\
\text { centrada en el } \\
\text { estudiantado y su } \\
\text { aprendizaje. Un estilo } \\
\text { de }\end{array}$ \\
\hline & $\begin{array}{l}\text { Formar ciudadanía } \\
\text { crítica } \\
\text { Organizar y presentar } \\
\text { el conocimiento de } \\
\text { forma comprensible }\end{array}$ & $\begin{array}{l}\text { criticidad de los } \\
\text { conocimientos } \\
\text { estudiados }\end{array}$ & alternativo. \\
\hline
\end{tabular}

En la Tabla 6, la agrupación e interpretación según las modalidades de respuesta de las variables: p.1.4. El papel del estudiantado y p.1.8. las actividades-estrategias que predominan en la clase. Su representación en la Figura 6 muestra una inercia de $80,9 \%$ y tres agrupaciones. 
TABLA 6

El papel del estudiantado y las actividades-estrategias que predominan en la clase

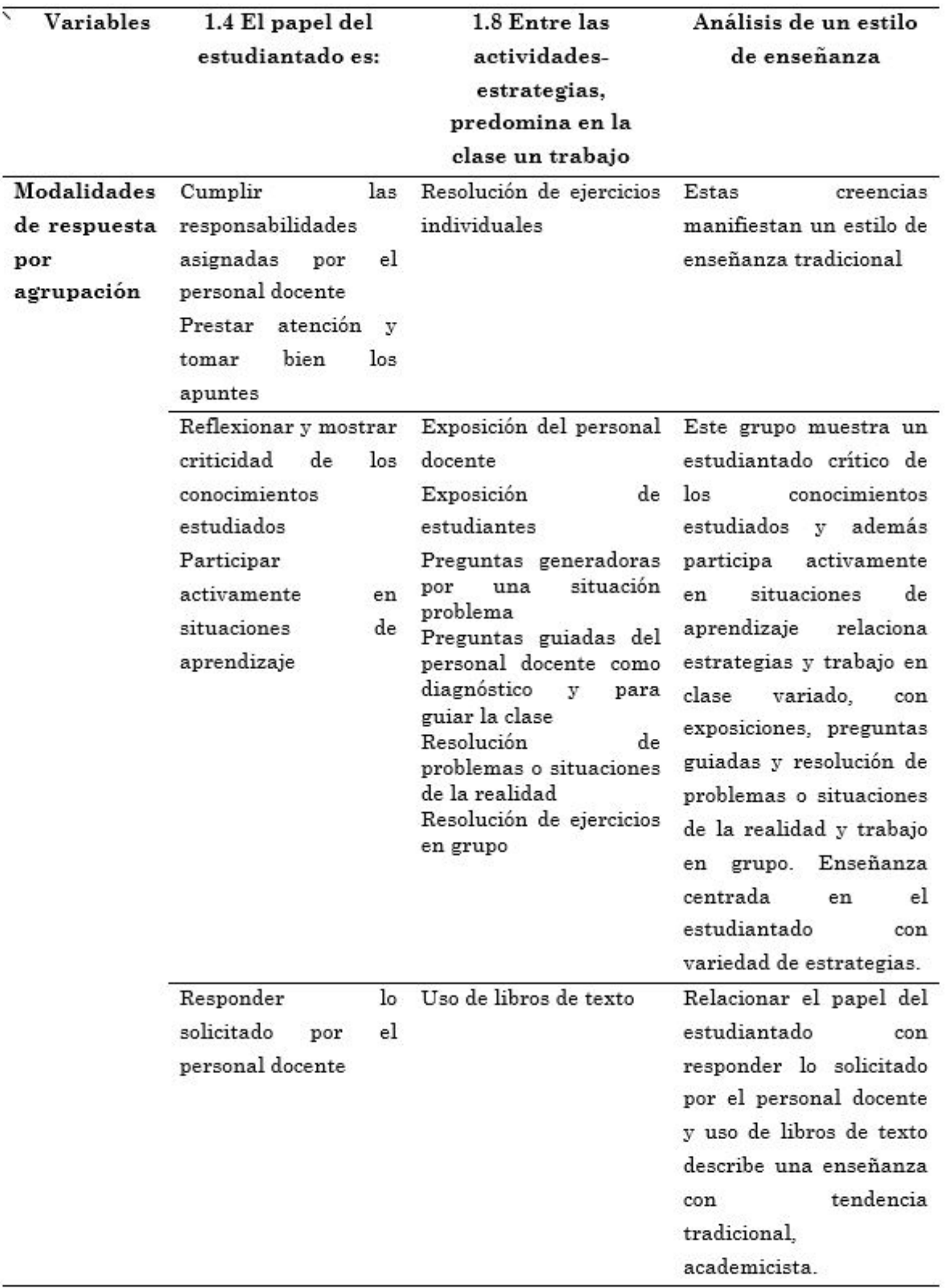




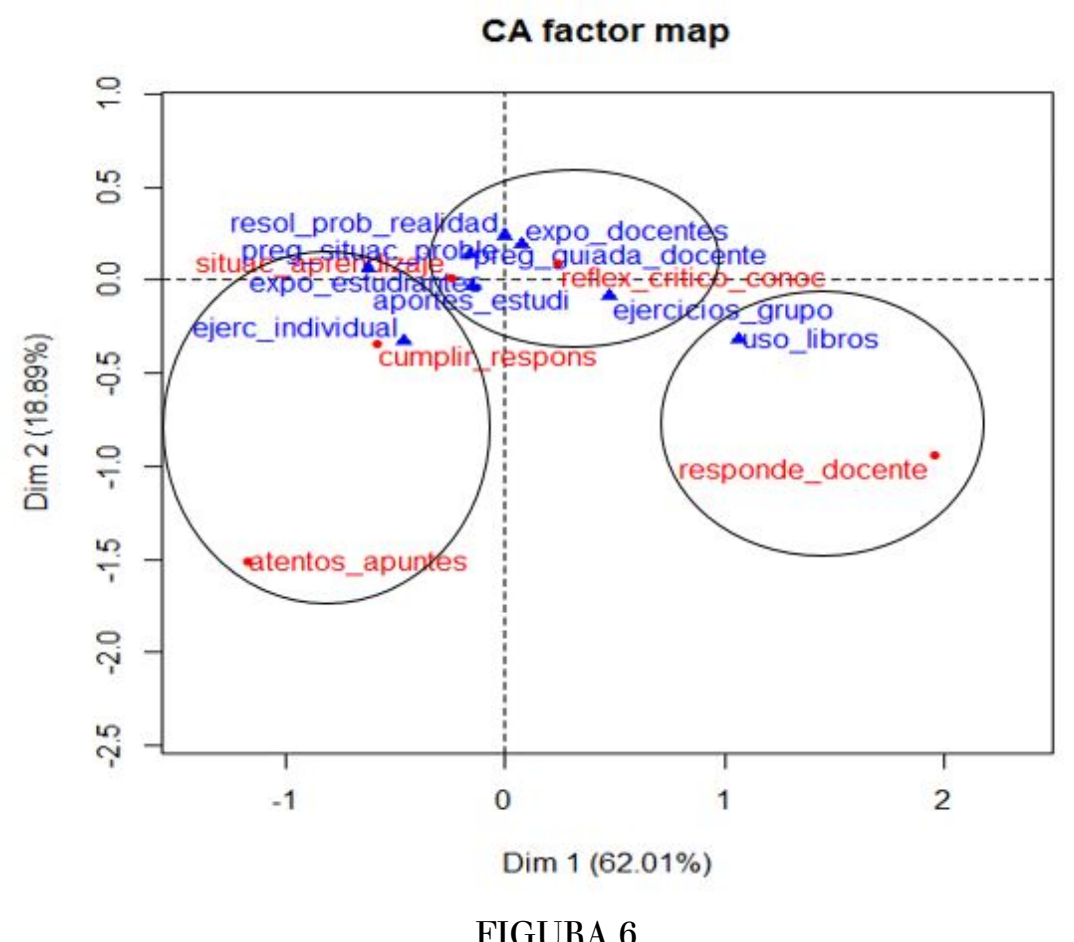

Relación de las modalidades de respuesta de las preguntas 1.4 y 1.8

Para la relación de las preguntas: p.1.4 el papel del estudiantado y p.1.7 la organización de actividades en la clase, el AFC arroja como resultado dos grupos, los mismos se representan en la Figura 7 esta agrupación presenta una inercia de $89,74 \%$, conformándose dos grupos. 


\section{CA factor map}

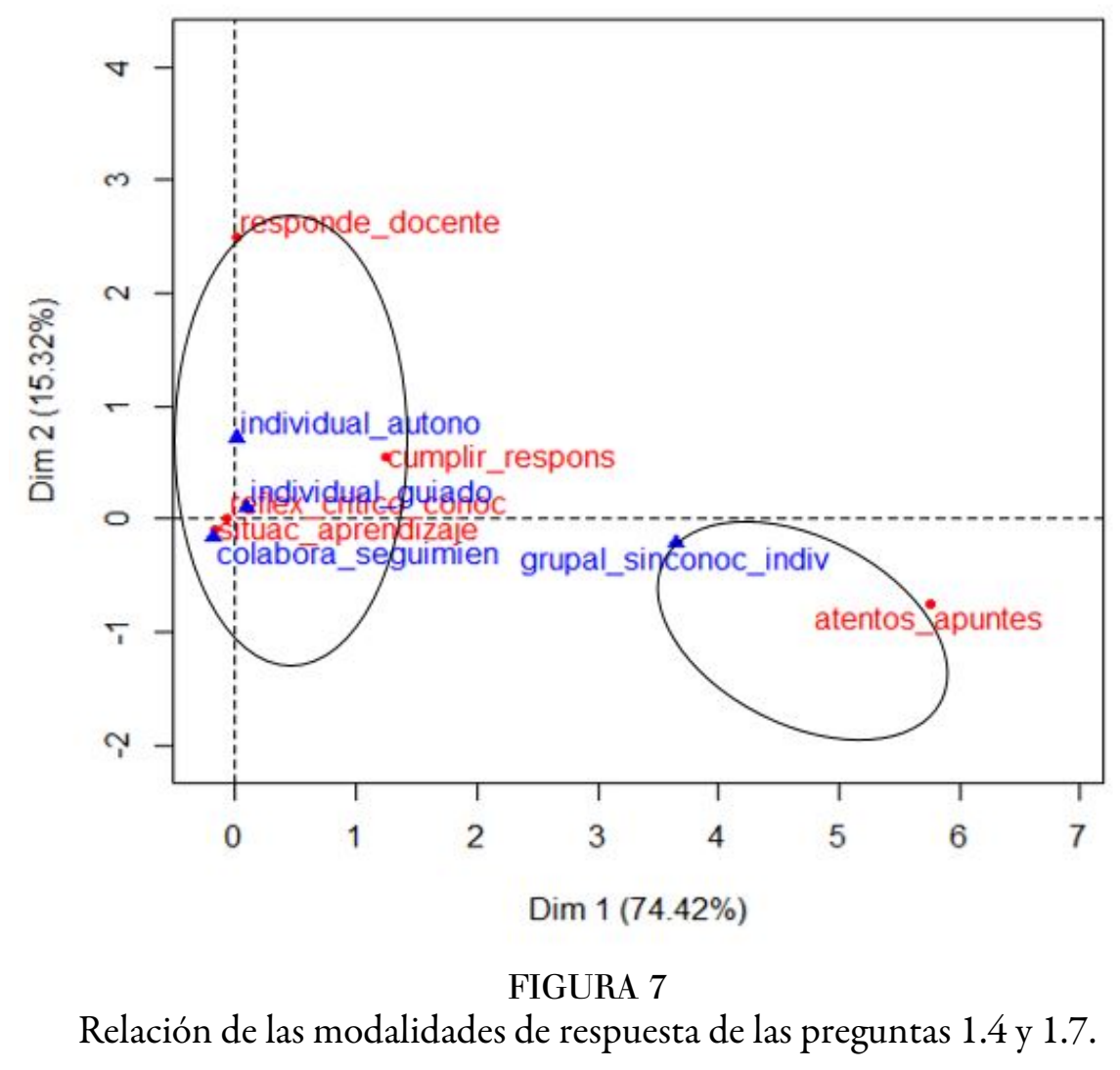

El primer grupo evidencia un estilo de enseñanza que promueve un papel activo del estudiantado donde se organizan actividades con seguimiento al trabajo individual por parte del personal docente. Estilo de enseñanza constructiva, mientras que el segundo limita el papel del estudiantado a prestar atención y tomar bien los apuntes, con una organización grupal sin determinar el trabajo de cada estudiante. Situación que podría deberse a grupos numerosos y deja la responsabilidad de su aprendizaje al estudiantado.

\section{Conclusiones}

El análisis factorial de correspondencias como metodología permitió trabajar resultados provenientes de variables cualitativas, la inercia alta indica buena representación en los resultados. Estos se proyectan en planos cartesianos, lo que permite analizar la relación entre modalidades de respuestas de docentes, aspecto que agrupa formas de pensar y acciones comunes, para caracterizar estilos de enseñanza.

Las agrupaciones que se generan presentan rasgos de estilos tradicionales o alternativos, con participaciones pasivas o activas de estudiantes en el trabajo de aula que promueve el personal docente.

La epistemología de la matemática tiene sus particularidades que el personal docente interpreta y cree, esto se manifiesta en el desarrollo de sus clases. Los resultados representados en las Figuras 8, 9 y 10 ponen en evidencia ciertas características comunes de los estilos de enseñanza del personal docente de matemática graduado de la Universidad de Costa Rica, de acuerdo con las respuestas agrupadas en estas creencias epistemológicas. 


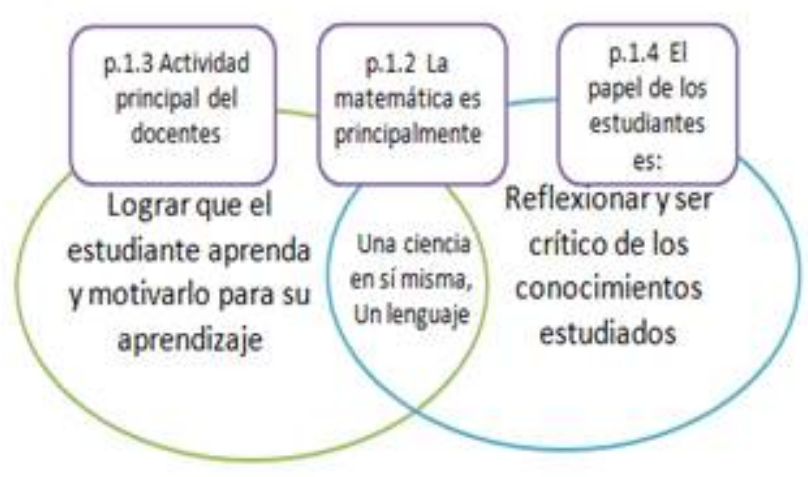

FIGURA 8

Características comunes según modalidad de respuesta (preguntas 1.2, 1.3 y 1.4).

En la relación representada en la Figura 9 se parte de la creencia de que la matemática es una ciencia en sí misma y un lenguaje, relación que agrupa características de un estilo de enseñanza centrado en los conocimientos y en el aprendizaje.

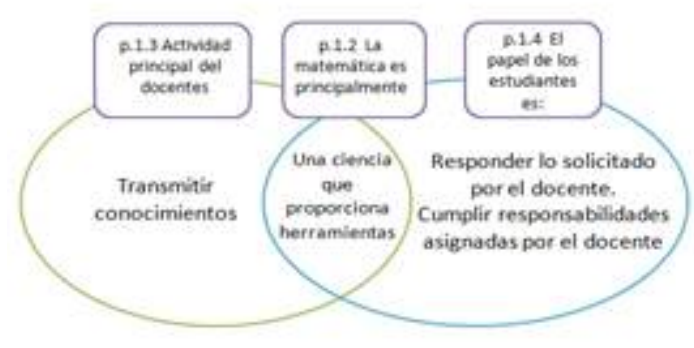

\section{FIGURA 9}

Características comunes según modalidad de respuesta (preguntas 1.2, 1.3 y 1.4).

En la relación representada en la Figura 10 se percibe un grupo de docentes con rasgos de un estilo de enseñanza práctico

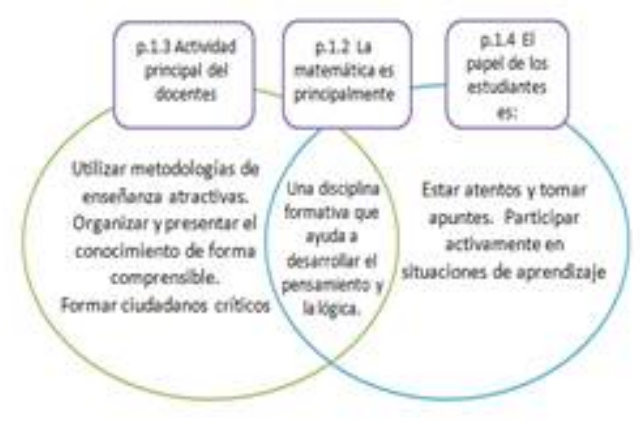

FIGURA 10

Relación entre las modalidades de respuesta de las preguntas 1.2, 1.3 y 1.4. 
En el grupo caracterizado en la Figura 11, se parte de la creencia de que la matemática es una disciplina formativa que ayuda a desarrollar el pensamiento y la lógica, las actividades principales del personal docente son variadas, pero también está la de formar ciudadanía crítica y estudiantado que está atento, toma apuntes y participa activamente en situaciones de aprendizaje. Lo anterior presenta rasgos de un estilo de enseñanza centrado en el estudiantado.

$\mathrm{Al}$ considerar las formas de trabajo que utiliza el personal docente para el desarrollo de las clases y las creencias acerca de la naturaleza, enseñanza y aprendizaje de la matemática, se dilucida una manera que se ha interpretado y aceptado en las instituciones costarricenses, la cual se manifiesta en un estilo de enseñanza práctico.

Las creencias epistemológicas acerca del aprendizaje podrían describir docentes con estilos de enseñanza que promueven clases donde el estudiantado construye su conocimiento o más directivas, que evocan un rango entre un estilo de enseñanza alternativo y un estilo de enseñanza tradicional.

Se observa que las respuestas de docentes que consideran la matemática una disciplina formativa, también la relacionan con la importancia y utilidad que se le atribuye en el desarrollo de las personas, su razonamiento, lógica, orden y otras habilidades. Posiblemente el personal docente valorará "el chispazo", la heurística empleada y las ideas para el razonamiento en la resolución de problemas, sin importar la precisión en la escritura y el resultado. Se valora el aporte de la matemática integralmente en la formación del estudiantado, como lo amplía Pinto (2012), el formar en valores y en formas de convivencia cada vez más humanas, tiene que ver con conceptos epistemológicos, antropológicos y éticos, lo que sin duda lleva al personal docente a comprender su acción educativa como "formadora" y no meramente instruccional.

Considerar la matemática como herramienta para otras disciplinas muestra la relación con distintos campos donde se aplican las matemáticas como herramienta para la resolución de problemas, en este caso posiblemente el personal docente se ocupe de proponer ejemplos y plantear problemas aplicados en distintas disciplinas.

En el caso de considerar principalmente la matemática como ciencia, podría creerse que es para unas cuantas personas, las que presenten habilidades o intereses.

En el caso de creer que la matemática es principalmente un lenguaje, el docente se ocupará posiblemente de la rigurosidad por escribir bien matemáticamente y la precisión en el significado de conceptos.

Si se considera la matemática como las distintas formas de resolver problemas, el personal docente se centrará en los procedimientos y las recetas prácticas para la resolución de problemas, y mostrará variedad y aplicaciones en distintas áreas disciplinarias.

Las creencias epistemológicas de cómo se enseña matemática, vinculan la práctica en una enseñanza que transmite los contenidos y evalúa para comprobar si se han adquirido o bien ofrecer posibilidades para que el mismo estudiantado construya sus propios conocimientos.

Los estilos de enseñanza del docente podrían ofrecer información para comprender los estilos de aprendizaje que se promueven en el estudiantado, la influencia y las condiciones que se han establecido para el desarrollo de las clases, resultados que permitirán reflexionar en los aspectos que podrían condicionar o influir en la actitud hacia la matemática y las formas de aprender de estudiantes. Así como comprender las complejidades que se presentan en la enseñanza.

Una teoría de enseñanza de la matemática debe dar cuenta del momento histórico y cultural que vive la sociedad, los resultados ofrecen herramientas explicativas e interpretativas de grupos con ciertas características.

La epistemología de la educación matemática tiende a responderse con modelos o estilos docentes diversos, la docencia no es una actividad adaptable a modelos, sino que cada docente crea elementos para su propio modelo, que responda a las necesidades y particularidades que enfrenta. 
El personal docente de matemática resuelve, desde su práctica, aspectos epistemológicos, que tienen implicaciones en el estilo de enseñanza que desarrolla, tales como, si el estudiantado está aprendiendo con las estrategias de enseñanza que utiliza, creencia poco reflexionada desde la formación.

Estos resultados sobre un estilo de enseñanza confrontan la interpretación de la labor diaria, la forma de interactuar, de describir las actividades que se desarrollan en los procesos de enseñanza y aprendizaje que se promueven, pero también acerca de la construcción de la propia profesionalidad.

El análisis factorial de correspondencias como metodología permitió trabajar resultados provenientes de variables cualitativas, lo cual abre posibilidades de relacionar modalidades de respuestas entre informantes, aspecto importante para describir patrones o comportamientos, lo cual enriquece los análisis y las representaciones en investigaciones en educación.

\section{REFERENCIAS}

Abello, D. M y Hernández, C. (2010). Diseño y validación de un modelo teórico e instrumental para la identificación de estilos de enseñanza en docentes universitarios (Tesis de maestría). Universidad Pedagógica Nacional, Bogotá. Recuperado de:http://repository.pedagogica.edu.co/handle/20.500.12209/7588

Blanco, L. y Guerrero, E. (2002). Estudio preliminar sobre la influencia de las emociones y los estilos cognitivos ante la tarea académica. En F.Castro y M. I. Fajardo (Coords.). Psicología de la educación y formación del profesorado. Nuevos retos, nuevas respuestas. INFAD.

Bonilla, F. S. (1986). Estilos de enseñanza en la Universidad de Costa Rica. Revista Educación, 10(2): 99-114.

Caballero, A. (2008). El domínio afectivo em las matemáticas de los estudiantes para maestro de la Facultad de Educación de La Universidad de Extremadura (Manuscrito inédito). Universidad de Extremadura, España.

Chronaki, A. (2000). Teaching maths through theme-based resources: style pedagogic, theme and maths in lessons. Educational Studies in Mathematics, 42, 141-163.

Contreras, I. (1994). El rol del docente como objeto de estudio. Revista Educación. 18(1), 67-71.

Contreras, L. C. y Blanco, L. (2002). Aportaciones a la formación inicial de maestros en el área de matemáticas: Una mirada a la práctica docente. Cáceres: Servicio de Publicaciones de la Universidad de Extremadura.

De León, I (2006). Los estilos de enseñanza pedagógicos: Una propuesta de criterios para su determinación. Revista de investigación, 57, 69-97.

Evans, C. (2006). The relationship between the cognitive style(s) and preferred teacher style(s) of PGCE students. Durham University. E-These on line.

Francis, S. (2012). El conocimiento pedagógico del contenido como modelo de mediación docente. San José, Costa Rica: Coordinación Educativa y Cultural. CECC/SICA:.

Gargallo, B. (2008). Estilos de docencia y evaluación de los profesores universitarios y su influencia sobre los modos de aprender de sus estudiantes. Revista Española de pedagogía, 66(241), 425-446.

Gómez-Chacón, I. M. (2000). Matemática emocional. Los afectos en el aprendizaje matemático. Madrid: Narcea.

Gras, R. (1992). L'Analyse des donées: une méthodologie de traitement de questions de didactique. Recherches en didactique des mathématiques. 12(1), 59-72.

Heimlich, J., \& Norland, E. (2002). Teaching Style: Where are we now? New Directions for adult and continuing education, 93, 17-25.

Lafortune, L. (1992). Dimensión Affective en Mathématiques. Quebec, Canadá: Modulo Éditeur.

Lebart, M., \& Piron, X. (2000). Statistique exploratoire multidimensionnelle (2eme ed.). Paris: Editorial Dunod.

Martínez, P. (2009). Estilos de enseñanza: Conceptualización e investigación. En función de los estilos de aprendizaje de Alonso Gallego y Honey). Revista Estilos de Aprendizaje, 3(3), 1-16.

Oser, F. K. y Baeriswyl, F. J. (2001). Choreographies of Teaching: Bridging Instruction to Learning. En V. Richardson, (Ed.), Handbook of Research on Teaching (pp: 1031-1065). Aera. 
Pinto, R. (2012). Principios filosóficos y epistemológicos del ser docente. San José, Costa Rica: Editorial Coordinación Educativa y Cultural Centroamericana (CECC/SICA).

Ponte, J. P. (1999). En K. Krainer, y F. Goffree (Eds.), On research in teacher education: From a study of teaching practices to issues in Teacher education (pp.43-50, traducción resumida de Casimira López). Osnabrück: Forschungsintitut für Mathematikdidactik.

Rodríguez, O. (2007). Correspondence Analysis for Simbolic Multi-Valued variables. Recuperado de http:// www.oldemarrodriguez.com/yahoo_site_admin/assets/docs/SymCA_CARME2007.229151706.pdf

Sierpinska, A. y Lerman, S. (1996). Epistemologies of matematics and of mathematics education. En A. J. Bishop, M.A.K. Keitel-Kreidt, C. Kilpatrick \& J. Laborde (Eds.), International Handbook of mathematics Education (pp. 827-876, traducción por Juan Godino). Dordrecht, HL: Kluwe, A.P.

Vázquez, R.M.y Ángulo, J.F. (2010). El currículum en la acción: las tareas de enseñar y aprender. El análisis del método. En J. Gimeno (Comp.), Saberes e incertidumbres sobre el curriculum (PP. 333-354). Madrid, España: Ediciones Morata

Vaughn, L. y Baker, R. (2008). Do different Pairings of Teaching Styles and Learning Styles Make a Difference? Preceptor and Resident Perceptions. Teaching and Learning in Medicine, 20(3), 239-247. 


\section{Anexo 1}

ANEXO 1

Tabla sobre modalidades de respuesta, etiquetas y códigos de los ítems 1.2, 1.3, 1.4, 1.9 y 3.2 del cuestionario EEDM

\begin{tabular}{|c|c|c|}
\hline Ítems & Modalidades de respuesta & Etiquetas \\
\hline $\begin{array}{l}1.2 \text { Es la } \\
\text { matemática } \\
\text { principal } \\
\text { mente } \\
\text { (seleccione } \\
\text { una } \\
\text { opción): }\end{array}$ & $\begin{array}{l}\text { 1=Una disciplina formativa que ayuda a } \\
\text { desarrollar el pensamiento y la lógica } \\
\text { 2=Una disciplina que ayuda a encontrar } \\
\text { distintas formas de resolver un problema } \\
\text { 3=Un lenguaje } \\
\text { 4=Una ciencia que proporciona } \\
\text { herramientas a otras disciplinas } \\
5=\text { Una ciencia en sí misma } \\
6=\text { Otra: }\end{array}$ & $\begin{array}{l}\text { 1=Pensamiento_logica } \\
2=\text { Resolver_problema } \\
3=\text { Lenguaje } \\
\text { 4=Herramientas_disciplinas } \\
5=\text { Ciencia_sí_misma } \\
6=\text { Otra }\end{array}$ \\
\hline $\begin{array}{l}\text { 1.3 La } \\
\text { actividad } \\
\text { principal del } \\
\text { personal } \\
\text { docente es } \\
\text { (seleccione } \\
\text { una } \\
\text { opción): }\end{array}$ & $\begin{array}{l}\text { 1=Lograr que estudiantes aprendan } \\
\text { 2=Impartir contenidos } \\
\text { 3=Utilizar metodologías de enseñanza } \\
\text { atractivas } \\
\text { 4=Motivar a estudiantes por aprender } \\
\text { 5=Formar ciudadanía crítica } \\
\text { 6=Organizar y presentar el conocimiento } \\
\text { de forma comprensible } \\
7=\text { Otra: }\end{array}$ & $\begin{array}{l}\text { 1=estudiante_aprenda } \\
2=\text { Impartir_contenidos } \\
\text { 3=metodologias_atractivas } \\
\text { 4=Motivar_aprender } \\
5=\text { ciudadanos_criticos } \\
6=\text { forma_comprensible } \\
7=\text { otra }\end{array}$ \\
\hline $\begin{array}{l}\text { 1.4 El papel } \\
\text { de } \\
\text { estudiantes } \\
\text { es } \\
\text { (seleccione } \\
\text { una } \\
\text { opción): }\end{array}$ & $\begin{array}{l}\text { 1=Poner atención y tomar bien los apuntes } \\
2=\text { Participar activamente en situaciones } \\
\text { de aprendizaje } \\
3=\text { Responder lo solicitado por sus docentes } \\
4=\text { Cumplir las responsabilidades } \\
\text { asignadas por sus docentes } \\
5=\text { Reflexionar y mostrar criticidad de los } \\
\text { conocimientos estudiados } \\
6=\text { Otra: }\end{array}$ & $\begin{array}{l}1=\text { atentos_apuntes } \\
2=\text { situac_aprendizaje } \\
3=\text { responde_docente } \\
4=\text { cumplir_respons } \\
5=\text { reflex_critico_conoc } \\
6=\text { otra }\end{array}$ \\
\hline $\begin{array}{l}1.9 \text { Usted } \\
\text { promueve } \\
\text { como forma } \\
\text { de } \\
\text { aprendizaje, } \\
\text { (seleccione } \\
\text { la principal } \\
\text { opción): }\end{array}$ & $\begin{array}{l}\text { 1=Ejercicios laboriosos para que recuerden } \\
\text { procedimientos } \\
2=\text { Plantear la resolución de un problema } \\
\text { por etapas (Descubrimiento guiado) } \\
3=\text { Trabajo libre (Descubrimiento } \\
\text { autónomo) } \\
\text { 4=Diferentes formas de razonamiento } \\
\text { (lógico, espacial, algebraico...) } \\
\text { 5=Reflexión y cuestionamiento de lo } \\
\text { estudiado (Pensamiento crítico) } \\
6=\text { Resolver lista de ejercicios para } \\
\text { desarrollar destrezas } \\
7=\text { Otro: }\end{array}$ & $\begin{array}{l}1=\text { ejerci_laboriosos } \\
2=\text { resol_prob_etapas } \\
3=\text { trabajo_libre } \\
4=\text { diferente_razonami } \\
5=\text { reflex_cuestionami } \\
6=\text { resol_ejercicios } \\
7=\text { otro }\end{array}$ \\
\hline $\begin{array}{l}3.2 \text { Cree } \\
\text { usted que el } \\
\text { personal } \\
\text { docente } \\
\text { influye } \\
\text { principalme } \\
\text { nte en } \\
\text { (seleccione } \\
\text { una } \\
\text { opción): }\end{array}$ & $\begin{array}{l}\text { 1=El rendimiento académico de sus } \\
\text { estudiantes } \\
\text { 2=La actitud de sus estudiantes hacia los } \\
\text { contenidos o la materia } \\
\text { 3=La motivación para el aprendizaje } \\
4=\mathrm{La} \text { participación activa de sus } \\
\text { estudiantes en la clase } \\
\text { 5=El desarrollo integral de sus estudiantes } \\
6=\mathrm{Las} \text { relaciones interpersonales entre } \\
\text { estudiantes } \\
7=\text { Otro: }\end{array}$ & $\begin{array}{l}1=\text { rendi_academico } \\
2=\text { actitud_estudiantes } \\
3=\text { motivacion_aprendi } \\
4=\text { parti_activa_estudi } \\
5=\text { desarro_integral } \\
6=\text { relaciones_interper } \\
7=\text { otro }\end{array}$ \\
\hline
\end{tabular}


Revista Educación, 2018, 42(2), ISSN: 0379-7082 / 2215-2644

Nota: Elaboración propia

\section{Notas}

[1] Estudio que forma parte de la tesis doctoral titulada: Estilos de enseñanza del docente de Matemática de la carrera de Enseñanza de la Matemática en la Universidad de Costa Rica.

\section{BY-NC-ND}

